Article

\title{
Sustainable Decisions on Product Upgrade Confrontations with Remanufacturing Operations
}

\author{
Lin Sun ${ }^{1,2}$, Lingjiang Zhang ${ }^{3,4, *(1)}$ and Youwei $\mathrm{Li}^{5}$ \\ 1 School of Management and Economics, University of Electronic Science and Technology of China, \\ Chengdu 611731, China; sunlin@cdut.cn \\ 2 The Business school, Chengdu University of Technology, Chengdu, 610059, China \\ 3 College of Communication Art, Chongqing University of Posts and Telecommunications, \\ Chongqing 400000, China \\ 4 School of Construction Management and Real Estate, Chongqing University, Chongqing 400030, China \\ 5 The Business School, University of Hull, Hull HU6 7RX, UK; Youwei.li@hull.ac.uk \\ * Correspondence: zhanglingjiang@cqupt.edu.cn
}

Received: 5 October 2018; Accepted: 5 November 2018; Published: 7 November 2018

check for

\begin{abstract}
In recent decades, remanufacturing is perceived to be an environmentally friendly option due to the reduced consumption of materials, energy etc. It should be noted that whether the remanufacturing operations are undertaken by the original equipment manufacturers (OEMs) or outsourced to the remanufacturers, given the size and the growth of remanufactured products, many OEMs intend to fend off the potential cannibalization of new products sales through differentiating their quality levels from those of remanufactured ones by launching upgraded versions. To understand whether and how the product upgrading strategy impacts on optimal outcomes in the context of the remanufacturing operations undertaken by OEMs or third-party remanufacturers (TPRs), in this paper, we develop two models that highlight the OEM's product upgrading strategy under the scenarios where (1) the OEM owns its remanufacturing operations in-house (Model O) or (2) remanufacturing operations are undertaken by a TPR (Model T). Among other results, we find that, from an economic performance perspective, it is more beneficial for the OEM to perform remanufacturing operations in-house; however, from an environmental sustainability perspective, such behavior is not always good for our environment. In particular, when the level of product upgrading is pronounced, the remanufacturing operations undertaken by the OEM are always detrimental to our environment, due to indulging in remanufacturing, as seen in Model $\mathrm{O}$.
\end{abstract}

Keywords: sustainability; environmental impacts; product upgrading; remanufacturing; game theory

\section{Introduction}

The global business community has recently experienced a dramatic increase of interest in sustainability issues [1]. For example, we have seen the fact that many original equipment manufacturers (OEMs) have created business models where remanufacturing is an essential part. After receiving a contract from the US Army for the remanufacturing of $222 \mathrm{CH}-47$ helicopters, $13 \mathrm{CH}-47 \mathrm{~F}$ helicopters, and six new CH-47F helicopters, in May 2017, Boeing was awarded a $\$ 488$ million contract to remanufacture AH-64 Apache attack helicopters for the United Kingdom [2]. It is estimated that the remanufacturing industry contributes about $£ 2.4$ billion per year to the British economy. Also, it could be increased to $£ 5.6$ billion in 2020 with appropriate support [3]. Furthermore, a rough assessment of resource impact suggests that remanufacturing also saves more than 800,000 tons of $\mathrm{CO}_{2}$ emissions per annum [4].

Although remanufacturing may be accompanied with a profitable and/or green environment reputation, incorporating remanufacturing into existing business models may lead to the serious 
cannibalization of new products sales. According to the results of auctions, consumers usually underestimate the price of the remanufactured product by $15.3 \%$ lower compared to new products [5]. Furthermore, many consumers usually associate the lower prices for remanufactured items with the OEM brand [6]; such behavior creates an even more difficult challenge for OEMs to engage with remanufacturing operations directly. Undoubtedly, the potential for the cannibalization of new product sales by remanufacturing is a central issue for OEMs when they consider the integration of remanufacturing operations into their existing business models [5].

As a result, on the other hand, we can also observe a surge of activity where many other OEMs do not choose to remanufacture their products, but they outsource it to the third-party remanufacturers (TPRs) [7]. In practice, TPRs have built $\$ 100+$ million per year in remanufacturing businesses [8]. According to a survey from the US remanufacturing industry, OEMs only accounted for a small fraction (about 6\%) of the total firms that have integrated remanufacturing operations [9]. Similar cases have also appeared in developing countries. For example, in 2008, the pilot program for automobile parts remanufacturing entered into effect in the China market. In this program, besides several OEMs, many TPRs have been supported by the China National Development and Reform Commission to engage in remanufacturing for auto parts [10]. Obviously, cannibalization may become even fiercer when the OEM confronts remanufacturing from TPRs due to their remanufacturing operations not being under the control of the OEM.

Whether the remanufacturing operations are undertaken by the OEMs or outsourced to the remanufacturers, given the size and the growth of remanufactured products, many OEMs intend to fend off the potential cannibalization of new products sales through differentiating their quality levels from remanufactured ones by launching upgraded versions [11]. More specifically, many OEMs usually reduce the value of remanufactured units by often releasing newer versions that are incompatible or only partially compatible with old versions. For example, as many auto repair shops engage in remanufacturing operations, the revenue from remanufacturing has grown year by year, and remanufactured auto parts are becoming more competitive substitutes for new auto parts. To deal with the potential for cannibalization from remanufactured vehicles, Dodge continues its commercial vehicle market offensive with a barrage of product enhancements that will deliver enhanced capability, power, and safety to commercial customers- "With strategic upgrades, we will continue to enhance our commercial vehicle lineup to better serve the needs of our business customers" said Scott Kunselman, Vice President-Dodge Truck, Chrysler LLC [12]. Similarly, Xerox and Kodak have reduced the purchase behavior for remanufactured photocopier equipment by designing their photocopiers and micrographic equipment with more functions [13].

Is the product upgrading strategy impacts delivering optimal outcomes in the context of the remanufacturing operations that are undertaken by OEMs or TPRs, and how? From an economic perspective, intuitively, product upgrading strategies seemingly reduce the cannibalization of new products and beneficial for OEMs. From the environmental sustainability angle, however, the implications of product upgrading decisions are not clear. To understand this fundamental question, in this paper, we develop two models that highlight the OEM's product upgrading strategy under the scenarios of (1) all remanufactured products are provided by the OEM (Model O); or (2) remanufacturing operations are undertaken by a TPR (Model T). Using both models, we strive to answer the following questions:

(1) Is there any difference in the incentive of product upgrading between Model $\mathrm{O}$ and T?

(2) From the economic perspective, which strategy is more beneficial for OEM and TPR?

(3) From a sustainability perspective, which strategy is more beneficial for our environment?

(4) Lastly, what is the role of the product upgrading strategy in shaping optimal decisions?

We find that, to deal with cannibalization from remanufactured products, the OEM has a higher incentive for product upgrading in Model T than in Model O. This difference would lead the OEM to provide more remanufactured products in Model T. More importantly, indulging on remanufacturing 
is not always good for our environment. In particular, our analysis further reveals that, when the level of product upgrading is pronounced, the OEM undertakes remanufacturing operations that are always detrimental to our environment. On the other hand, from an economic performance perspective, we demonstrate that outsourcing remanufacturing operations to TPRs is always detrimental to the OEM.

This paper therefore has a twofold contribution. On the one hand, although the implications of remanufacturing operations on sustainable issues have been well studied (see, e.g., [14-17]), whether and how product upgrading strategies impact on sustainable issues is not clear. As such, we complement this stream of literature by allowing the OEM to have the flexibility to upgrade its products under different scenarios of remanufacturing, respectively. On the other hand, even though numerous researchers have highlighted product upgrade strategies under various settings, (see, e.g., [18-20]), the role that the product upgrading strategy of the OEMs plays in shaping equilibrium decisions of remanufacturing operations is not all clear. We thus extend them to consider cases that highlight how products upgrade strategies impact on the optimal strategy's choice under the remanufacturing operations that are undertaken by the OEMs and/or TPRs, respectively.

The remainder of the paper is structured as follows. In Section 2, we review the related literature, and in Section 3, we provide the model framework for both scenarios. Section 4 then demonstrates how the product upgrading strategy impacts on the optimal strategies choice under the remanufacturing operations undertaken by the OEMs and/or TPRs, and presents the main results; subsequently, we illustrate our major results with a numerical example in Section 4. Last, we conclude our work and provide future research directions in Section 6.

\section{Literature Review}

Accompanied with a profitable and/or green environment reputation, remanufacturing is increasingly being recognized among more researchers. In particular, motivated by the fact that the disposable camera is a product where the firm benefits from the cost reduction, while charging full price for the remanufactured product, Ferrer and Swaminathan [14] study a firm that makes new products in the first period and uses returned cores to offer remanufactured products, along with new products, in future periods. However, Yan et al. [15] complement the former by considering both economic and environmental issues related to different channels structures for marketing remanufactured products. Subsequently, Zhu et al. [16], based on the influence of customer bargaining behavior, study several different scenarios of centralized decision-making, decentralized decision-making, and contract coordination, using Stackelberg game theory. More recently, Yan et al. [17] pay their attention on the question of whether OEMs should also outsource their reverse channels to third-party remanufacturers when outsourcing remanufacturing and reveal that the OEM conducting take-back operations itself can achieve the overall better outcomes for all economic, social, and environmental situations. In addition, Fera et al. [21,22] develop several cost models for additive manufacturing and propose the additive manufacturing as a potential technologic answer to the remanufacturing issues. As mentioned earlier, although the implications of remanufacturing operations on sustainable issues have been well studied in the above literature, whether and how product upgrading strategies impact on sustainable issues is not clear. In this paper, we complement this stream of literature by allowing the OEM to have the flexibility to upgrade its products under different scenarios of remanufacturing, respectively. As such, we complement this stream of literature by allowing the OEM to have the flexibility to upgrade its products under different scenarios of remanufacturing, respectively.

The second stream of literature relevant to this paper is on product upgrading strategies. In particular, Banerjee and Soberman [18] intend to focus on how a firm's product development capability affects the launch strategy for a durable product that is sequentially improved over time in a market where consumers have heterogeneous valuations for quality and show that firms' launch strategies are affected by the degree to which consumers think ahead. Conversely, Klastorin et al. [19] develop a game theory model that examines the effect of a firm's preannouncement of its product 
development, and show that, under some conditions, the innovator firm can benefit by preannouncing its product and giving the imitator firm additional time to differentiate its product. Xiong et al. [20] establish a two-period model in which a monopolistic manufacturer sells new durable products directly to end consumers in both periods, while a third-party entrant operates a reverse channel by selling used products in the secondary market, and they find that when upgrades are typically small or moderate, the upgrading of new products can increase a third-party entrant's profitability in the secondary market. We refer the interested reader to Adams et al. [23] for a more detailed review on product innovation strategies. Even though the above literature has highlighted product upgrade strategies under various settings, the role that the product upgrading strategy of the OEMs plays in shaping equilibrium decisions of remanufacturing operations is not all clear. We thus extend them to consider cases that highlight how products upgrade strategies impact on the optimal strategy's choice under the remanufacturing operations that are undertaken by the OEMs and/or TPRs, respectively.

Our work is particularly relevant to Li et al. [24]; using a stylized model of endogenous product quality improvement and remanufacturing, the authors find that the main driver of the contradicting results is a change in manufacturing costs that is caused by improving the product quality. However, we differentiate from them in several pronounced aspects: First, based on the observations from current practice that, in the USA remanufacturing market, only $6 \%$ remanufacturers were OEMs [9], and we allowed the OEM the flexibility of outsourcing its remanufacturing to TPRs. Second, our aim and model setting are quite different. For example, besides highlighting the effects of product quality improvement on the OEM's remanufacturing efforts, we extend them to address the role that the product upgrading strategy of the OEMs plays in shaping profits or sustainability issues in the context of the remanufacturing operations undertaken by TPRs. Finally, our analysis reveals that, in contrast to the economic performance, if the level of product upgrading is pronounced, the action of the OEM undertaking remanufacturing operations is always detrimental to our environment.

\section{Problem Setting and Modeling}

We considered an OEM that distributes all new products but has the flexibility of remanufacturing all cores in-house (Model O) or outsourcing them to an independent TPR (Model T). As with prior studies by Savaskan et al. [25] and Ferrer and Swaminathan [26], we assumed that in our both models, all cores for remanufacturing are obtained from new products in the market; that is, any given unit has only two lives: one as a new product and one as a remanufactured product.

Since the decisions around introducing a new version require significant lead times, we followed Li et al. [24] and Atasu and Souza [27] and assumed that the sequence starts in Stage 1 with the OEM deciding whether to introduce a new upgraded version. Both parties then choose their optimal responses in marketing: the OEM first announces its license fees for remanufacturing $(f)$ to the independent TPR, who responds by announcing the optimal quantities of remanufactured products $\left(q_{r}\right)$. Meanwhile, the OEM chooses the optimal number of units of new products $\left(q_{n}\right)$ that would be sold in the same market.

Please note that, as with Li et al. [24] and Atasu and Souza [27], in our both models, the OEM can take the strategic decision of whether to provide the upgraded version for new products. More specifically, if the OEM does not invest into research and development (R\&D), it would remain with the existing generation of new products. If the OEM invests into R\&D, then the upgraded version with improved quality will be available in the market. As in prior studies of Banker et al. [28] and Albert et al. [29], we modeled the content differentiation between the upgraded version and the existing version with vertical differentiation of quality and assumed that, if the OEM introduces the upgraded version, it increases the customers' valuation of the existing model by a factor $\theta=1+\delta$, where $\delta>0$ represents the degree of content differentiation between the upgraded version and the existing version (where the quality is normalized to 1 [11]).

Suppose that the investment cost function that is associated with the R\&D output is a convex cost function of $K(\theta-1)^{2} / 2$. Similar forms of response functions have been widely used in the literature 
for investments in R\&D and in quality improvement (see, e.g., Atasu and Souza [27], Vives [30], and Yin et al. [11]). Obviously, if no new version is released, i.e., the OEM remains with the existing products; that is, $\theta=1$, then no investment is required. To enable a focus on the difference of the costs with manufacturing and remanufacturing characteristics, as in Xiong et al. [7] and Zou et al. [31], we assumed that the manufacturing cost of the new product is $c_{n}$, and that the remanufacturing cost is $c_{r}$. Please note that, since remanufacturing is usually accompanied with a lower cost than that of manufacturing [7], as with Yin et al. [11], we further assumed that making a remanufactured product is less costly than producing a new one, as per Yan et al. [15]; $c_{n}=c>c_{r}=0$.

To capture the fact that consumers' willingness to pay for most products are different, consistent with Ferrer and Swaminathan [26], we used the parameter $v_{n}$ to represent a consumer's valuation of the services provided by an existing product, which is distributed uniformly between 0 and 1 . Like Xiong et al. [7], Yin et al. [11] and Zou et al. [31], the net utility of the consumer with type $v_{n}$ that derives from a new product depends on their valuation and the price; that is, $U_{n}=\theta v_{n}-p_{n}$. Please note that we used the parameter $\theta=1+\delta$ to represent the degree of difference between the existing and upgraded versions (i.e., $\delta \geq 0$ ).

In stage 2, all new and remanufactured products were available in the same market. To reflect the fact that there is a cannibalization of new product sales by remanufactured ones, as per Yan et al. [15] and Debo et al. [32], the primary consumer will value-discount the remanufactured product as a fraction $k(0 \leq k \leq 1)$ of the willingness to pay for the new one, that is, $k v_{n}$. Given the willingness to pay for the remanufactured products, the net utility of the consumer with type $v_{n}$ is $U_{r}=k v_{n}-p_{r}$. Based on the above two willingness-to-pay functions, we can obtain the inverse demand functions as follows:

$$
\begin{gathered}
p_{n}=\theta\left(1-q_{n}\right)-k q_{r}, \\
p_{r}=k\left(1-q_{n}-q_{r}\right) .
\end{gathered}
$$

The details of all parameters are listed in Table 1.

Table 1. Parameters in both models.

\begin{tabular}{cc}
\hline Notation & Definition \\
\hline$c_{n} / c_{r}$ & The production cost of the new / remanufactured products \\
$K$ & The cost scaling parameter for product upgrading \\
$\theta$ & The degree of difference between the existing and upgraded versions \\
$k$ & The consumer value-discount for remanufactured products \\
$f$ & The license fees charged to the independent TPR \\
$c_{n} / c_{r}$ & The production cost of the new / remanufactured products \\
$q_{n}^{i} / q_{r}^{i}$ & The quantity of new / remanufactured products in Model $j \in\{O, T\}$ \\
$\pi_{i}^{j}$ & The profit of player $i \in\{0, t\}$ under Model $j$ \\
$e^{j}$ & The environmental impacts in Model $j$ \\
\hline
\end{tabular}

\subsection{Model O}

We used $\pi_{i}^{j}$ to represent the profit of player $i \in\{o, t\}$ under Model $j \in\{O, T\}$, where the subscript $i \in\{0, t\}$ refers to the players of OEM and TPR, while the superscript $j \in\{O, T\}$ denotes Models $O$ and $\mathrm{T}$, respectively. Since all new and remanufactured products are provided by the OEM in Model $\mathrm{T}$, then the sequence of events is as follows: the OEM first decides on whether to introduce a new upgraded version, and then determines the optimal quantities of new and remanufactured products $\left(q_{n}\right.$ and $\left.q_{r}\right)$.

Based on the inverse demand functions in Equation (1), then the OEM's problem in Model O can be written as:

$$
\max _{q_{n}, q_{r}} \pi_{o}^{O}\left(\theta, q_{n}, q_{r}\right)=\left(p_{n}-c\right) q_{n}+p_{r} q_{r}-K(\theta-1)^{2} / 2
$$


where the first two terms are the OEM's profit from selling new and remanufactured products, respectively, while the last term is the potential cost for product upgrading. Solving the first-order condition (FOCs) of (2), we can obtain the optimal units of the new and remanufactured products, i.e., $q_{n}^{\mathrm{O} *}$ and $q_{r}^{\mathrm{O} *}$, respectively.

To analyze the role played by product upgrading, we should compare the OEM's profit under the scenario with product upgrading (or no product innovation). It is noted that this comparison would lead a threshold $K<K^{O}$, below which the OEM would release a new version of the product. All equilibrium decisions and profits are listed in Table 1 (For clarity, all proofs are provided in the Appendix A).

\subsection{Model T}

In Model T, the OEM would distribute all new products, while it outsources the remanufacturing operations to the TPR; as such, the OEM's and the TPR's problems are:

$$
\begin{aligned}
\max _{q_{n}} \pi_{o}^{T}\left(f, q_{n}^{*}, q_{r}^{*}\right) & =\left(p_{n}-c\right) q_{n}^{*}+f q_{r}^{*}-K(\theta-1)^{2} / 2 \\
\max _{q_{r}} \pi_{t}^{T}\left(f, q_{n}^{*}, q_{r}^{*}\right) & =\left(p_{r}-f\right) q_{r}^{*}
\end{aligned}
$$

Solving the first-order condition of (3) yields optimal quantities of both products (i.e., $q_{n}^{T *}$ and $q_{r}^{T *}$ ). Substituting them into the profits of the OEM, we can then rewrite the OEM's problems as follows:

$$
\max _{f} \pi_{o}^{T}\left(f, q_{n}^{*}, q_{r}^{*}\right)=\left(p_{n}-c\right) q_{n}^{*}+f^{*} q_{r}^{*}-K(\theta-1)^{2} / 2
$$

Solving the first-order condition of (4) yields optimal patent license fees $\left(f^{*}\right)$ that are charged to the TPR. As before, to analyze the role played by product upgrading, we need to compare the OEM's profit under a scenario of product upgrading with that of no product upgrading. This would lead another threshold, $K<K^{T}$, below which the OEM would release a new version of the product (see, Table 2.)

Table 2. Equilibrium decisions and profits.

\begin{tabular}{l}
\hline Remanufacturing undertaken by OEM (Model O) \\
\hline Optimal decisions: $q_{n}^{O *}=\frac{\theta-k-c}{2(\theta-k)}, q_{r}^{O *}=\frac{\theta-k}{2 c} ;$ \\
\hline Optimal profits: $\pi_{0}^{O *}=\frac{\theta^{2}+c^{2}+2 \theta c-2 \theta c-\theta k}{4(\theta-k)}-K(\theta-1)^{2} / 2$ \\
\hline Threshold value of $\mathrm{K}: K^{O}=\frac{\theta+k^{2}-\theta k-k-c^{2}}{2(\theta-1)(\theta-k)(1-k)}$ \\
\hline Remanufacturing undertaken by TPR (Model T) \\
\hline Optimal decisions: $q_{n}^{T *}=\frac{8 \theta^{2}-8 \theta c-3 \theta k+c k}{16 \theta^{2}-6 k \theta}, q_{r}^{T *}=\frac{8 \theta-3 k}{2 c}, f=\frac{8 \theta^{2}-3 \theta k-c k}{2 \theta(8 \theta-3 k) k} ;$ \\
\hline Optimal profits: $\pi_{0}^{T *}=\frac{8 \theta^{3}-16 \theta^{2} c-3 \theta^{2} k+8 \theta c^{2}+6 \theta k c+k c^{2}}{4 \theta(8 \theta-3 k)}-K(\theta-1)^{2} / 2 ; \pi_{t}^{T *}=\frac{4 c^{2} k}{4(8 \theta-3 k)^{2}}$ \\
\hline Threshold value of K: $K^{T}=\frac{64 \theta^{2}-24 \theta^{2} k-64 \theta c^{2}+9 \theta k^{2}-8 \theta c^{2} k-24 \theta k-8 c^{2} k+3 c^{2} k^{2}}{2 \theta(\theta-1)(8 \theta-3 k)(8-3 k)}$ \\
\hline
\end{tabular}

\section{Analysis}

In this section, we intend to answer the question posed at the beginning of this paper: the role that the product upgrading strategy of the OEMs plays in shaping profits or sustainability issues in the context of the remanufacturing operations undertaken by OEMs or TPRs, respectively. To do so, we first addressed the differences in optimal decisions between the two models. We then addressed the differences in the incentives of product upgrading under both models. Subsequently, we highlighted the differences in economic performance and environment sustainability. Lastly, we focused on the role that the product upgrading strategy plays in shaping economic performance and environment stability. 


\subsection{Comparison of Optimal Decisions}

In this subsection, by comparing the optimal decisions listed in Table 1, we obtained the following proposition that highlight the differences in the optimal decisions between the two models.

Proposition 1. The optimal units of new (remanufactured) products in Model O are always lower (higher) than that in Model T; that is, $q_{n}^{O}<q_{n}^{T}\left(q_{r}^{O}>q_{r}^{T}\right)$.

Please note that both products are available from the OEM in Model O. Conversely, in Model $\mathrm{T}$, all remanufactured products are provided by the TPR, while new products are distributed by the OEM. As a result, the OEM is more likely to distribute greater quantities of remanufactured products in Model O due to the following two reasons: First, when the TPR is endogenized, the classic double marginalization problem resurfaces, which leads to selling remanufactured products in Model O being more profitable for the OEM than that of wholesaling them to the TPR. As a result, the OEM would care less about the potential cannibalization of new products sales and provide greater quantities of remanufactured products in Model $\mathrm{O}$, though the higher units of remanufactured products can cannibalize the sales of new products. On the other hand, in Model $\mathrm{T}$, those new products are distributed by the OEM directly, while all remanufactured products are available from the TPR. This would lead the marginal revenue from the remanufactured product to be relative lower than that from selling new products. As such, in Model T, the OEM would be likely to choose relatively higher quantities for new products, which would limit the units of remanufactured products that are sold by TPR and reduces cannibalization from the remanufactured ones.

Similarly, regarding the quantities of new products in Model O being higher than those in Model $\mathrm{T}$, we can interpret them as follows. As mentioned earlier, the quantity of remanufactured in Model $\mathrm{O}$ is higher than that in Model T. This means that the new product's potential market is relative lower in Model $\mathrm{O}$ than that in Model T. As such, as Proposition 1 shows, compared to Model T, the OEM provides less new products in Model O.

\subsection{Comparison of Incentives in Product Upgrading}

In this subsection, we now move to an analysis of the role that the product upgrading strategy of the OEMs plays in the context of the remanufacturing operations that are undertaken by OEMs or TPRs. Said differently, by comparing the optimal decisions listed in Table 1, we can summarize the differences in the incentive of product upgrading under both models as follows.

Proposition 2. The OEM always has a higher incentive to release a new version when outsourcing the remanufacturing operations to the TPR; that is, $K^{O}<K^{T}$.

Proposition 2 reveals that, compared to Model O, the OEM has a higher incentive to upgrade products when outsourcing the remanufacturing operations to the TPR. This can be interpreted as follows. Since the TPR is an independent member that maximizes profits from remanufacturing only, the potential for the cannibalization of new products becomes a concern under the scenario of the remanufacturing outsourcing [33]. As a result, the OEM sees the competition of the remanufactured products from the TPR as a fierce battle; to maximize its own profit, the OEM has a higher incentive to invest into R\&D to differentiate its new products from those of remanufactured ones and restores the its monopolistic premium.

Proposition 2 reveals an important phenomenon: the incentive of product upgrading in Model T is always higher than that in Model O. That is, there is an "escape competition" effect for the OEM facing competitive pressure from the TPR, an argument that is supported by Arrow [34], who suggests that an innovator is likely to protect their property rights by further innovation, as this allows them to "escape" the negative effects of competition and gives them an additional monopoly profit. However, Proposition 2, it should be noted, differs from the findings of [34], and a great difference is that, rather 
than highlighting the competition between new products, we focus on the OEM's R\&D incentives under the potential cannibalization of new products from remanufactured ones.

\subsection{Comparison of Economic Performance}

In this subsection, we now pay attention to the differences in economic performance between the two models. More specifically, we intend to answer the question, from the economic perspective, of which strategy is more beneficial for the OEM, as follows.

Proposition 3. Outsourcing remanufacturing operations to the TPR is always detrimental to OEM; that is, $\pi_{o}^{T *}<\pi_{0}^{O *}$.

Proposition 3 is quite consistent with the traditional wisdom that remanufacturing operations undertaken by the TPR are usually detrimental to the OEM [35]. The underlying intuition behind this is as follows. In Model O, both products are distributed by the OEM, conversely, in Model T, all remanufactured products are provided by the TPR, while the new products are distributed by the OEM. As a result, the OEM benefits less in Model T because it is the monopoly supplier under Model $\mathrm{O}$, but it has to compete with those remanufactured units from the TPR in Model T. Put differently, although the competition from the TPR induces the OEM's sales volume of new products to be higher, such behavior would reduce the marginal revenue per unit. In addition, furthermore, the benefits from the sales volume of new products is not enough to "compensate" for the profit "loss", due to the decrease in marginal revenue per unit.

\subsection{Comparison of Environmental Sustainability}

In this subsection, we mainly focus on sustainability issues from an environmental perspective: which model is more beneficial for our environment?

Although many methods can be used to measure environmental sustainability, (Life Cycle Assessment) LCA is quite a common way to calculate the environmental impact of a strategy by summing over all the life-cycle phases from raw material procurement to end of life [27,36]. A detailed literature review on LCA techniques in the remanufacturing industry is available in [37,38]. Please note that LCA is the "compilation and evaluation of the inputs, outputs, and the potential environmental impacts of a product system throughout its life cycle". Accordingly, as with Atasu and Souza [27] and Liu et al. [39], we define $e_{n}, e_{u}, e_{r}$, and $e_{d}$ as the impact of new product marking, usage, remanufacturing, and disposal, respectively. Let $e^{T} / e^{O}$ refer to the total environmental impact of Model T/O, respectively. We can then summarize our key findings as follows.

Proposition 4. If $u>u_{1}$, outsourcing the remanufacturing operations to the TPR is beneficial for our environment (i.e., $e^{O}>e^{T}$ ); otherwise, the opposite is true.

Traditional wisdom suggests that remanufacturing conserves the raw materials, and that it is good for our environment $[7,15]$. This logic, however, misses a key point: to obtain more cores for remanufacturing, the OEM may overproduce new and/or remanufactured products. In particular, compared to Model T, the OEM would distribute more quantities of both products; that is, $q_{n}^{O}+q_{r}^{O}>q_{n}^{T}+q_{r}^{T}$. This would lead to a higher total environmental impact of use by consumers in Model $\mathrm{O}$. Additionally, the total environmental impact on remanufacturing is also higher in Model $\mathrm{O}$. When $u<u_{1}$, these two environmental impacts are sufficient to "compensate" for environmental impacts' "loss" in production and disposal, which leads the total environmental impacts in Model O to be higher than that in Model T; that is, $e^{O}>e^{T}$.

It should be noted that, Proposition 3 reveals that, compared to outsourcing remanufacturing operations to the TPR, OEM can benefit more by undertaking such operations itself because the OEM is more likely to produce greater quantities of remanufactured products in Model O (see, Proposition 1). 
In contrast, Proposition 4 shows that overincentivizing on remanufacturing is not always good for our environment, an argument that is supported by Li et al. [9], who reveal that, from the perspective of the environment, although remanufacturing is good on a per-unit basis, it may actually be harmful in terms of total resource consumption. As mentioned earlier, it should be noted that our aim and model setting are quite different. For example, they do not pay any attention to the question of how product upgrade strategies impact on the optimal strategy choices under the remanufacturing operations undertaken by TPRs.

This discordant in economic and sustainability objectives informs the managers that undertaking the remanufacturing operations, but not outsourcing it, is the better choice if they just care about the economic performance. Conversely, from the government policy maker's perspective, the above discordant in economic and sustainability objectives shows that outsourcing the remanufacturing operations to the TPR is beneficial for our environment. In addition, the discordant in economic and sustainability objectives further show that it is not necessary to incentivize the firm to do remanufacturing.

\subsection{The Role Played by the Product Upgrading Strategy}

Our analysis has so far addressed the differences between the issues of the incentives, economic performance, and environmental sustainability of product upgrading. Below, we extend our analysis on the product upgrading decision by highlighting the role that the product upgrading strategy plays in shaping them. In particular, we can summarize our key findings as follows.

Proposition 5. As the level of product upgrading increases, the difference of economic performance decreases, while the difference of the environmental sustainability/incentive product upgrading increases.

An increase in the level of product upgrading means that the difference of new products from those of remanufactured ones increases, which means that the increase of premium prices for new products are faster than that of remanufactured ones. Furthermore, as Proposition 1 showed, the OEM is more likely to distribute higher quantities of new products, but fewer units for remanufactured products in Model T. As such, the difference of economic performance decreases with the level of product upgrading, due to there being a faster increase in revenue from new products in Model $\mathrm{T}$ (equaling to the price premium for a new version times its sales volume in Model T) than that in Model O. Meanwhile, the OEM's incentives in product upgrading between both models decrease, due to more units of new products being distributed in Model $\mathrm{T}$ than that in Model O. Lastly, the difference of environmental sustainability increases with the level of product upgrading, due to the higher incentives of product upgrading in Model T.

\section{Numerical Examples}

We have addressed, so far, the role that the product upgrading strategy of the OEMs plays in shaping profits or sustainability issues in the context of the remanufacturing operations from a theoretical perspective. To gain a comprehensive review on variations in optimal decisions, we now visualized our major results in numerical experiments.

Please note that, Esenduran [40] argued that the ratio of producing cost to market size at range of [0.1, 0.5]. As prior research of Liu et al. [39], normalized the potential market size to 1 and set $c=0.4$. Since the consumer value-discount for remanufactured products usually varies from $45-90 \%$ [41,42], we also set $k=0.7$ in this numerical experiment. In addition, to calculate the total environmental impacts per product, we consider four life-cycle phases: production, use, disposal, and remanufacturing. All parameters in this numerical experiments were similar to the case correspond to the LCD industry setting in Liu et al. [39]; that is, we set $i_{n}=2073, i_{u}=853, i_{r}=600, i_{d}=0.226$ and $i_{d}=0.226$, respectively. All figures are obtained from numerical experiments in MATLAB 2014. 
First, we pay our attention to the difference in equilibrium decisions between both models. Based on Figure 1a, we found that, as Proposition 1 shows, the quantity of new products in Model $\mathrm{O}$ is always lower than that in Model T; that is, $q_{n}^{O}<q_{n}^{T}$. Second, we further observed that as the level of product upgrading increases, the difference of optimal quantities of new products between both models increases. On the other hand, based on Figure 1b, we concluded that as in Proposition 1, the optimal units of remanufactured products in Model $\mathrm{O}$ are always higher than those in Model $\mathrm{T}$; that is, $q_{r}^{O}>q_{r}^{T}$. Furthermore, the difference of optimal quantities of remanufactured products between both models decreases with the level of product upgrading.

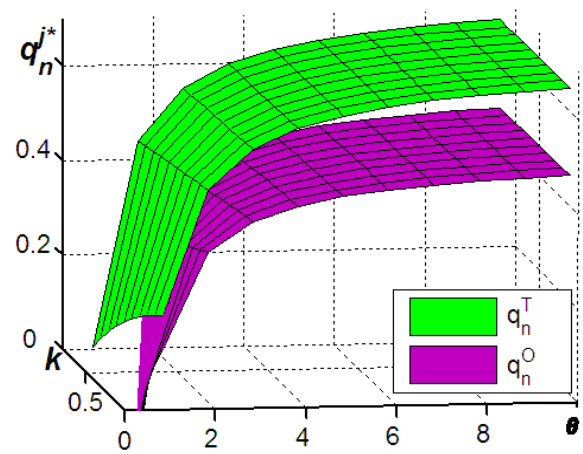

(a) Variations in $q_{n}^{j^{*}}$

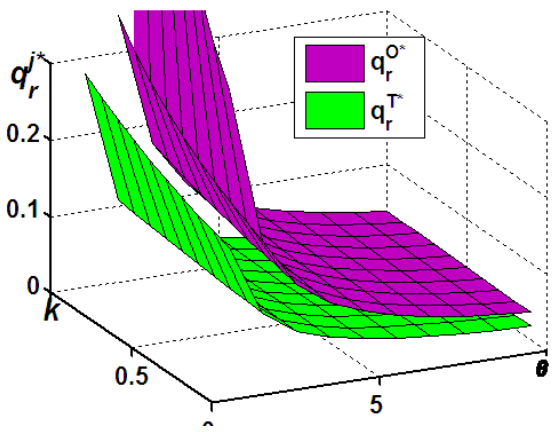

(b) Variations in $q_{r}^{j^{*}}$

Figure 1. Variations of optimal decisions.

We then move to the numerical experiments with the analysis of the role that the product upgrading strategy of the OEMs plays in the context of the remanufacturing operations that are undertaken by OEMs or TPRs. Figure 2 illustrates two important phenomena. First, as Proposition 2 shown, the incentive of releasing an upgraded version in Model $\mathrm{O}$ is always higher than that in Model $\mathrm{T}$, that is, $K^{O}<K^{T}$. In addition, the incentives of releasing an upgraded version in both models increase with the degree of difference between the existing and upgraded versions. Said differently, consistent with traditional wisdom, for any certain cost scaling of $K$, as the degree of difference between the existing and upgraded versions (i.e., the efficiency of R\&D investment) increases, the incentives of releasing an upgraded version in both models increase.

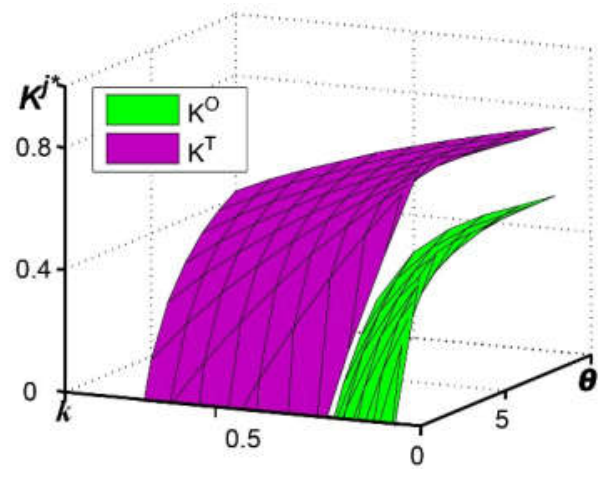

Figure 2. Variations of the incentives in product upgrading.

As the variation of the difference in economic performance between both models, Figure 3 illustrates two important phenomena (note that, consistent with prior research of Esenduran et al. [40], Subramanian and Subramanyam [41], we also set $k=0.7$ in this numerical experiments). First, as Proposition 3 shown, the OEM's profits in Model $\mathrm{O}$ are higher than that in Model T; i.e., $\pi_{o}^{T *}<\pi_{o}^{O *}$. Second, as the level of product upgrading increases, the difference in profits between both models 
decreases. More specifically, although the OEM's profits in both models increase with the level of product upgrading, the increasing level of profits in Model $\mathrm{T}$ is faster than that in Model $\mathrm{O}$.

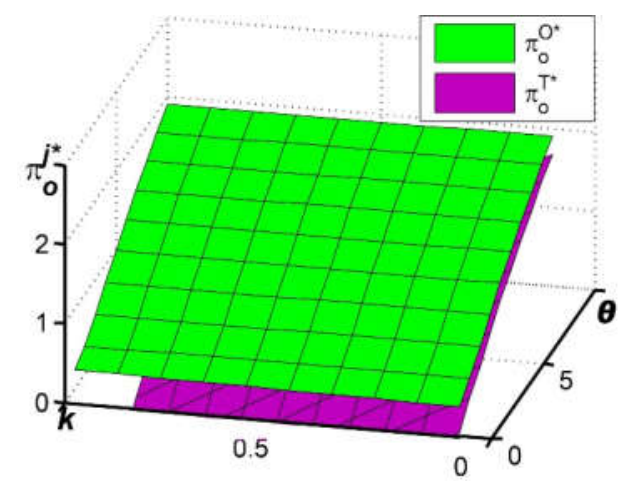

Figure 3. Variations of economic performance.

Last, we now illustrate the results in Proposition 4 with a numerical experiment. Based on Figure 4, we can conclude that, there is a threshold $u_{1}$, above which the environmental impacts of Model $\mathrm{T}$ is always lower than that in Model O. Put differently, as Proposition 4 shows, iff $u>u_{1}$, outsourcing the remanufacturing operations to the TPR is beneficial for our environment (i.e., $e^{O}>e^{T}$ ). In addition, the environmental impacts of both models increase with the degree of difference between the existing and upgraded versions.

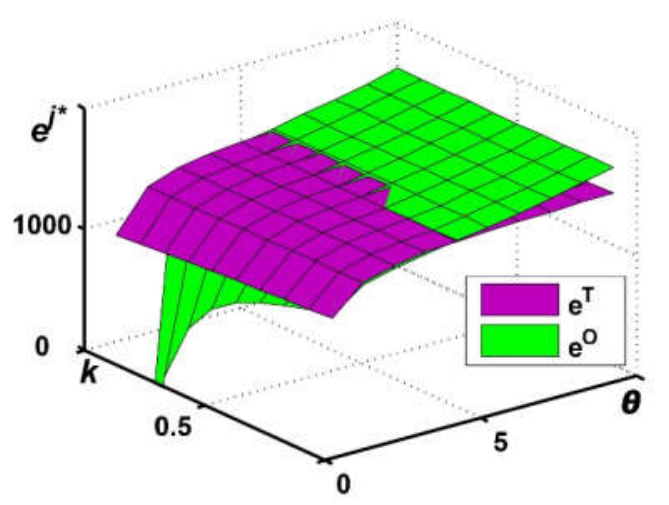

Figure 4. Variations of environmental sustainability.

\section{Conclusions}

Sustainability has recently experienced a dramatic increase in interest in recent decades [1]. Many managers have sought to integrate traditional operation management with sustainability issues, such as environment and earth resource preservation. In practice, as an alternative to manufacturing options, remanufacturing is generally perceived as a profitable and environmentally friendly option for many products. Whether OEMs own remanufacturing or outsource it to TPRs, the days of ignoring cannibalization problems and only focusing on the sale of new products are over for OEMs [39]. In practice, many OEMs intend to fend off the potential cannibalization of new product sales through differentiating the quality levels between both products by frequently launching upgraded versions for new products. For example, Xerox and Kodak reduce the possibility of purchase behavior for remanufactured photocopier equipment by designing their photocopiers and micrographic equipment with more functions. The product upgrading strategy is quite a common strategy that is used to deal with cannibalization problems from used products [11].

To understand whether and how the product upgrading strategies impact on optimal outcomes in the context of the remanufacturing operations undertaken by OEMs or TPRs, in this paper, we develop 
two models that highlight the OEM's product upgrading strategy under the scenarios of (1) all remanufactured products are provided by the OEM (Model O) or (2) remanufacturing operations are undertaken by a TPR (Model T). Using these two models, we intend to address the following research question: Is there any difference in the incentive of product upgrading between Models $\mathrm{O}$ and $\mathrm{T}$ ? From an economic perspective, which strategy is more beneficial for the OEM and TPR? From the sustainability perspective, which strategy is more beneficial for our environment? Lastly, what is the role that the product upgrading strategy plays in shaping on optimal decisions?

We find that outsourcing remanufacturing operations to TPRs is always detrimental to the OEM. Our analysis further reveals that, to deal with cannibalization problems from remanufactured products, the OEM has a higher incentive for product upgrading in Model $\mathrm{T}$ than that in Model O. In other words, the OEM has a higher tolerance for remanufacturing operations in Model $\mathrm{O}$ than that in Model T. Contrary to conventional wisdom, we demonstrate that such indulgent behavior for remanufacturing is not always good for our environment. In particular, we find that when the level of product upgrading is pronounced, the OEM undertakes remanufacturing operations that are always detrimental to our environment.

Future research will extend this paper in several directions. First, our both models are developed from operations management perspective and revealed that there is the discordancy in economic and sustainability objectives. The future literature can solve such contrasting results by jointly considering the effects of different firm strategic and organizational orientations (see, e.g., Ardito and Dangelico [42]). Second, we assume that the OEM is the monopoly supplier for making new and remanufactured products. However, in reality, it must compete with other agents in new and/or remanufactured markets. Third, our models assume that all decisions are analyzed in a single-period model, and although this is common in the literature of remanufacturing (see, e.g., Xiong et al. [7], Yan et al. [15], Savaskan et al. [25], and Liu et al. [39]), differentiating long-term decisions (product upgrading) from those of short-term decisions (i.e., remanufacturing operations) in multi-period models is a laudatory task. Finally, given our focus on sustainability issues, we have abstracted away other factors, including power structures, government policies, and asymmetric information. It will be interesting to see whether our results still hold under the relaxation of these assumptions.

Author Contributions: L.S. contributed to develop the model and write the paper; L.Z. contributed to collect motivate examples and related data; Y.L. contributed to strengthen all results' interpretation. All authors read and approved the final manuscript.

Funding: This research was funded by National Natural Science Foundation of China (71872028, 71763008, 71472026, and 71761020), the Major Programs of Sichuan Province Cyclic Economy Research Center (XHJJ-1801, XHJJ-1803 and XHJJ-1805).

Conflicts of Interest: The authors declare no conflict of interest.

\section{Appendix A. Technical Analysis for both Models}

Appendix A.1. Analysis of Model O

Plugging Equation (1) into Equation (2), the OEM's profits in Model O can be rewritten as follows.

$$
\max _{q_{n}, q_{r}} \pi_{o}^{O}\left(\theta, q_{n}, q_{r}\right)=\left(\theta\left(1-q_{n}\right)-k q_{r}-c\right) q_{n}+k\left(1-q_{n}-q_{r}\right) q_{r}-K(\theta-1)^{2} / 2
$$

Solving the FOCs of above equation, we can obtain that

$$
q_{n}^{O *}=\frac{\theta-k-c}{2(\theta-k)} \text { and } q_{r}^{O *}=\frac{\theta-k}{2 c}
$$


Plugging above optimal quantities into the OEM's profit, we can obtain that

$$
\pi_{o}^{O *}=\frac{\theta^{2}+c^{2}+2 \theta c-2 \theta c-\theta k}{4(\theta-k)}-K(\theta-1)^{2} / 2
$$

Clearly, the manufacturer prefers $\theta=1+\delta$ over $\theta=1+\delta$ if $K<K^{O}$, the opposite is true otherwise.

Where $K^{O}=\frac{\theta+k^{2}-\theta k-k-c^{2}}{2(\theta-1)(\theta-k)(1-k)}$ satisfies $\pi_{o}^{O *}(\theta=1)=\pi_{o}^{O *}(\theta=1+\delta)$. All equilibrium decisions and profits under Model $\mathrm{O}$ are presented in Table 1.

Appendix A.2. Analysis of Model T

Plugging Equation (1) into Equation (3), we can rewrite the OEM's and the TPR's profits in Model $\mathrm{T}$ as

$$
\begin{aligned}
& \max _{q_{n}} \pi_{o}^{T}\left(f, q_{n}^{*}, q_{r}^{*}\right)=\left(\theta\left(1-q_{n}\right)-k q_{r}-c\right) q_{n}^{*}+f q_{r}^{*}-K(\theta-1)^{2} / 2 \\
& \max _{q_{r}} \pi_{t}^{T}\left(f, q_{n}^{*}, q_{r}^{*}\right)=\left(k\left(1-q_{n}-q_{r}\right)-f\right) q_{r}^{*}
\end{aligned}
$$

Solving the FOCs of above Equations with $q_{n}$ and $q_{r}$ yields

$$
q_{n}=\frac{2 \theta-k+f-2 c}{4 \theta-k}, q_{r}=\frac{c k+k \theta-2 \theta f}{k(4 \theta-k)}
$$

Plugging $q_{n}^{T *}$ and $q_{r}^{T *}$ into the OEM's profit and solving FOC with $f$ to get $f^{*}=\frac{8 \theta^{2}-3 \theta k-c k}{2 \theta(8 \theta-3 k) k}$.

Plugging above optimal decisions into the OEM's profit, we can obtain that

$$
\pi_{o}^{T *}=\frac{8 \theta^{3}-16 \theta^{2} c-3 \theta^{2} k+8 \theta c^{2}+6 \theta k c+k c^{2}}{4 \theta(8 \theta-3 k)}-K(\theta-1)^{2} / 2
$$

Clearly, the manufacturer prefers $\theta=1+\delta$ over $\theta=1+\delta$ if $K<K^{T}$, the opposite is true otherwise.

Where $K^{T}=\frac{64 \theta^{2}-24 \theta^{2} k-64 \theta c^{2}+9 \theta k^{2}-8 \theta c^{2} k-24 \theta k-8 c^{2} k+3 c^{2} k^{2}}{2 \theta(\theta-1)(8 \theta-3 k)(8-3 k)}$ satisfies $\pi_{0}^{T *}(\theta=1)=\pi_{0}^{T *}(\theta=1+\delta)$. All equilibrium decisions and profits under Model $\mathrm{T}$ are presented in Table 1.

\section{Appendix B. Proofs}

Appendix B.1. Proof of Proposition 1

To prove $q_{n}^{O}<q_{n}^{T}$, we have to show that $q_{n}^{T}-q_{n}^{O}=\frac{c k(6 \theta-k)}{2 \theta(8 \theta-3 k)(\theta-k)}>0$. This is true for any $\theta \geq 1>k>0$. That is to say, $q_{n}^{O}<q_{n}^{T}$ is always holds.

To prove $q_{r}^{O}>q_{r}^{T}$, we have to show that $q_{r}^{O}-q_{r}^{T}=\frac{c(k+4 \theta)}{2(\theta-k)(8 \theta-3 k)}>0$. This is true for any $\theta \geq 1>k>0$. That is to say, $q_{r}^{O}>q_{r}^{T}$ is always holds.

Appendix B.2. Proof of Proposition 2

To prove $K^{O}<K^{T}$, we have to show that $K^{T}-K^{O}=\frac{c^{2} k\left(32 \theta^{2}+32 \theta-36 k \theta+8 k-11 k^{2}+3 k^{3}-11 \theta k^{2}+8 k \theta^{2}\right)}{2 \theta(\theta-1)(\theta-k)(k-1)(8 \theta-3 k)(3 k-8)}$. Since, $(k-1)<0,(3 k-8)<0$, but the rest of the items are all greater than zero for any $\theta \geq 1>k>0$, $K^{O}<K^{T}$ is always holds.

Appendix B.3. Proof of Proposition 3

To prove $\pi_{o}^{T *}<\pi_{o}^{O *}$, we have to show that $\pi_{o}^{O *}-\pi_{o}^{T *}=\frac{c^{2} k(4 u+k)}{4(u-k) u(8 u-3 k)}>0$.

This is true for any $\theta \geq 1>k>0$. That is to say, for any $\theta \geq 1>k>0, \pi_{0}^{T *}<\pi_{o}^{O *}$ is always holds. 
Appendix B.4. Proof of Proposition 4

Following Atasu and Souza [27] and Liu et al. [39], we can obtain that $e=$ $e_{n}+e_{u}+e_{r}+e_{d}=i_{n} q_{n}+i_{u}\left(q_{n}+q_{r}\right)+i_{r} q_{r}+i_{d} q_{n}$, as a result, we can obtain that $e^{T}=\frac{8 i_{n} \theta^{2}-8 i_{n} c \theta-3 i_{n} k \theta+i_{n} c k+8 i_{u} \theta^{2}-4 i_{u} c \theta-3 i_{u} k \theta+i_{u} c k+4 i_{r} c \theta+8 i_{d} \theta^{2}-8 i_{d} c \theta-3 i_{d} k \theta+i_{d} c k}{16 \theta^{2}-6 k u} ; \quad e^{O}=$ $\frac{i_{u} \theta-i_{n} k+i_{n} \theta-i_{n} c-i_{u} k+i_{r} c-i_{d} k+i_{d} \theta-i_{d} c}{2(\theta-k)}$.

Solving $e^{O}-e^{T}=\frac{4 i_{u} \theta^{2}-6 i_{n} k \theta-5 i_{u} k \theta+i_{i} \theta k-6 i_{d} k \theta+i_{n} k^{2}+i_{u} k^{2}+4 i_{r} \theta^{2}+i_{d} k^{2}}{2 c \theta(3 k-8 \theta)(\theta-k)}$. We can obtain that $\theta_{1}=$ $\frac{\left(5 i_{u}+6 i_{d}-i_{r}+6 i_{n}+\sqrt{9 i_{u}^{2}+44 i_{u} i_{d}+36 i_{d}^{2}+44 i_{u} i_{n}+72 i_{d} i_{n}+i_{r}^{2}+36 i_{n}^{2}-26 i_{r} i_{u}-28 i_{r} i_{d}-28 i_{r} i_{n}}\right) k}{8\left(i_{u}+i_{r}\right)}$ if $\theta>\theta, e^{O}-e^{T}>0$; otherwise, the opposite is true. That is to say, as Proposition 4 shown, if $\theta>\theta_{1}$, outsourcing the remanufacturing operations to the TPR is beneficial for our environment (i.e., $e^{O}>e^{T}$ ); otherwise, the opposite is true.

Appendix B.5. Proof of Proposition 5

$$
\frac{\partial\left(\pi_{0}^{O *}-\pi_{0}^{T *}\right)}{\partial \theta}=\frac{c^{2} k\left(22 \theta k^{2}+20 \theta^{2} k-64 \theta^{3}-3 k^{3}\right)}{4(\theta-k)^{2} \theta^{2}(8 \theta-3 k)^{2}} \text {. For any } \theta \geq 1>k>0 \text {, we can obtain that } \frac{\partial\left(\pi_{0}^{O *}-\pi_{0}^{T *}\right)}{\partial \theta}<0 .
$$

That is to say, for any $\theta \geq 1>k>0$, as the level of product upgrading increases, the difference of economic performance decreases.

$$
\frac{\partial\left(K^{T}-K^{O}\right)}{\partial \theta}=\frac{c^{2} k\left[\begin{array}{c}
176 \theta k^{2}+160 k \theta^{2}-512 \theta^{3}-24 k^{3}-194 \theta k^{3}-204 \theta^{2} k^{2}-9 k^{5} \\
+128 k \theta^{3}+512 \theta^{4}+18 k^{5} \theta-132 k^{4} \theta^{2}+338 k^{3} \theta^{3}+512 \theta^{5} \\
-352 \theta^{4} k^{2}+128 k \theta^{5}+33 k^{4}-1280 k \theta^{4}+616 k^{2} \theta^{3}+86 k^{3} \theta^{2}
\end{array}\right]}{(\theta-1)^{2}(\theta-k)^{2}(1-k) \theta^{2}(8 \theta-3 k)^{2}(3 k-8)}
$$

Since, $(3 k-8)<0$, but the rest of the items are all greater than zero for any $\theta \geq 1>k>0$, $\frac{\partial\left(K^{T}-K^{O}\right)}{\partial \theta}<0$ is always holds.

$$
\frac{\partial\left(e^{O}-e^{T}\right)}{\partial \theta}=\frac{c\left[\begin{array}{c}
32 i_{u} \theta^{4}+32 i_{r} \theta^{4}+90 i_{n} k^{2} \theta^{2}-96 i_{n} \theta^{3} k+67 i_{u} k^{2} \theta^{2} \\
-80 i_{u} \theta^{3} k-23 i_{r} k^{2} \theta^{2}+16 i_{r} \theta^{3} k+90 i_{d} k^{2} \theta^{2}-96 i_{d} \theta^{3} k \\
-22 \theta i_{n} k^{3}-22 \theta i_{u} k^{3}-22 \theta i_{d} k^{3}+3 i_{n} k^{4}+3 i_{u} k^{4}+3 i_{d} k^{4}
\end{array}\right]}{2 \theta^{2}(8 \theta-3 k)^{2}(\theta-k)^{2}}
$$

We can obtain that $\theta_{1}=\frac{\left(5 i_{u}+6 i_{d}-i_{r}+6 i_{n}+\sqrt{9 i_{u}^{2}+44 i_{u} i_{d}+36 i_{d}^{2}+44 i_{u} i_{n}+72 i_{d} i_{n}+i_{r}^{2}+36 i_{n}^{2}-26 i_{r} i_{u}-28 i_{r} i_{d}-28 i_{r} i_{n}}\right) k}{8\left(i_{u}+i_{r}\right)}$. If $\theta<\theta_{1}, \frac{\partial\left(e^{\mathrm{O}}-e^{T}\right)}{\partial \theta}<0$, while, $\theta>\theta_{1}, \frac{\partial\left(e^{\mathrm{O}}-e^{T}\right)}{\partial \theta}>0$.

It should be noted that, as Proposition 4 show, if $\theta>\theta_{1}, e^{O}-e^{T}>0$; otherwise, the opposite is true, that is to say, for any $\theta \geq 1>k>0$, as the level of product upgrading increases, the difference of the environmental sustainability increases.

\section{References}

1. Toffel, M.W. The growing strategic importance of end-of-life product management. Calif. Manag. Rev. 2003, 45, 102-129. [CrossRef]

2. Breitbart.com. Boeing Receives Apache Remanufacturing Contract for UK. Available online: https:// www.breitbart.com/news/boeing-receives-apache-remanufacturing-contract-for-uk/2017 (accessed on 8 September 2018).

3. Carbontrust.com. Supporting Excellence in UK Remanufacturing. Available online: https://www. carbontrust.com/resources/reports/advice/supporting-excellence-in-uk-remanufacturing/2015 (accessed on 26 January 2018).

4. Oakdene Hollins Ltd. Remanufacturing in the UK: A Significant Contributor to Sustainable Development? The Resource Recovery Forum: Skipton, UK, 2004.

5. Guide, J.V.D.R.; Li, J. The potential for cannibalization of new products sales by remanufactured products. Decis. Sci. 2010, 41, 547-572. [CrossRef] 
6. Ferguson, M. Strategic Issues in Closed-Loop Supply Chains with Remanufacturing; College of Management: Atlanta, GA, USA, 2009.

7. Xiong, Y.; Zhou, Y.; Li, G.; Chan, H.-K.; Xiong, Z. Don't forget your supplier when remanufacturing. Eur. J. Oper. Res. 2013, 230, 15-25. [CrossRef]

8. Cbronline.com. Big Players Emerge in Fragmented Brokerage Market. Available online: https: //www.cbronline.com/news/big_players_emerge_in_fragmented_brokerage_market (accessed on 18 September 2018).

9. Hauser, W.M.; Lund, R.T. The Remanufacturing Industry: Anatomy of a Giant: A View of Remanufacturing in America Based on a Comprehensive Survey across the Industry; Dept. of Manufacturing Engineering: Boston, MA, USA, 2008. Available online: www.bu.edu/reman (accessed on 18 October 2017).

10. The Administrative Measures for Pilot Remanufacturing of Automobile Parts \& Accessories (in Chinese). Available online: http://hzs.ndrc.gov.cn/newfzxhjj/zcfg/200810/t20081006_239458.html2008 (accessed on 1 January 2018).

11. Yin, S.; Ray, S.; Gurnani, H.; Animesh, A. Durable products with multiple used goods markets: Product upgrade and retail pricing implications. Mark. Sci. 2010, 29, 540-560. [CrossRef]

12. Aving Global Network. Dodge Continues Commercial Vehicle Market Offensive with Strategic Upgrades, Enhancements. Available online: http://us.aving.net/news/view.php?articleId=79161 (accessed on 8 September 2018).

13. Borenstein, S.; Mackie-Mason, J.K.; Netz, J.S. Antitrust policy in aftermarkets. Antitrust Law J. 1995, 63, 455-482.

14. Ferrer, G.; Swaminathan, J.M. Managing new and remanufactured products. Manag. Sci. 2006, 52, 15-26. [CrossRef]

15. Yan, W.; Xiong, Y.; Xiong, Z.; Guo, N. Bricks vs. clicks: Which is better for marketing remanufactured products? Eur. J. Oper. Res. 2015, 242, 434-444. [CrossRef]

16. Zhu, X.; Wang, J.; Tang, J. Recycling pricing and coordination of WEEE dual-channel closed-loop supply chain considering consumers' bargaining. Int. J. Environ. Res. Public Health 2017, 14, 1578. [CrossRef] [PubMed]

17. Yan, W.; Li, H.; Chai, J.; Qian, Z.; Chen, H. Owning or outsourcing? Strategic choice on take-back operations for third-party remanufacturing. Sustainability 2018, 10, 151. [CrossRef]

18. Banerjee, S.; Soberman, D.A. Product development capability and marketing strategy for new durable products. Int. J. Res. Mark. 2013, 30, 276-291. [CrossRef]

19. Klastorin, T.; Mamani, H.; Zhou, Y.P. To preannounce or not: New product development in a competitive duopoly market. Prod. Oper. Manag. 2016, 25, 2051-2064. [CrossRef]

20. Xiong, Y.; Zhao, P.; Xiong, Z.; Li, G. The impact of product upgrading on the decision of entrance to a secondary market. Eur. J. Oper. Res. 2016, 252, 443-454. [CrossRef]

21. Fera, M.; Fruggiero, F.; Costabile, G.; Lambiase, A.; Pham, D.T. A new mixed production cost allocation model for additive manufacturing. Int. J. Adv. Manuf. Technol. 2017, 92, 4275-4291. [CrossRef]

22. Fera, M.; Macchiaroli, R.; Fruggiero, F.; Lambiase, A. A new perspective for production process analysis using additive manufacturing-Complexity vs. production volume. Int. J. Adv. Manuf. Technol. 2017, 95, 1-13. [CrossRef]

23. Adams, R.; Jeanrenaud, S.; Bessant, J.; Denyer, D.; Overy, P. Sustainability-oriented innovation: A systematic review. Int. J. Manag. Rev. 2015, 18, 180-205. [CrossRef]

24. Li, G.; Reimann, M.; Zhang, W. When remanufacturing meets product quality improvement: The impact of production cost. Eur. J. Oper. Res. 2018, 271, 913-925. [CrossRef]

25. Savaskan, R.C.; Bhattacharya, S.; Wassenhove, L.N.V. Closed-loop supply chain models with product remanufacturing. Manag. Sci. 2004, 50, 239-252. [CrossRef]

26. Ferrer, G.; Swaminathan, J.M. Managing new and differentiated remanufactured products. Eur. J. Oper. Res. 2010, 203, 370-379. [CrossRef]

27. Atasu, A.; Souza, G.C. How does product recovery affect quality choice? Prod. Oper. Manag. 2013, 22, 991-1010. [CrossRef]

28. Banker, R.D.; Khosla, I.; Sinha, K.K. Quality and competition. Manag. Sci. 1998, 44, 1179-1192. [CrossRef]

29. Albert, H.; Xiaoyang, L.; Javad, N. Quality in supply chain encroachment. Manuf. Serv. Oper. Manag. 2015, $18,280-298$. 
30. Vives, X. Innovation and competitive pressure. J. Ind. Econ. 2008, 56, 419-469. [CrossRef]

31. Zou, Z.-B.; Wang, J.J.; Deng, G.S.; Chen, H. Third-party remanufacturing mode selection: Outsourcing or authorization? Trans. Res. Logist. Trans. Rev. 2016, 87, 1-19. [CrossRef]

32. Debo, L.G.; Toktay, L.B.; Wassenhove, L.N.V. Market segmentation and product technology selection for remanufacturable products. Manag. Sci. 2005, 51, 1193-1205. [CrossRef]

33. Atasu, A.; Guide, V.D.R.; Van Wassenhove, L.N. So what if remanufacturing cannibalizes my new product sales? Calif. Manag. Rev. 2010, 52, 56-76. [CrossRef]

34. Arrow, K.J. Economic welfare and the allocation of resources for invention. In The Rate of Direction of Inventive Activity: Economic and Social Factors; Nelson, R.R., Ed.; Princeton University Press: Princeton, NJ, USA, 1962; pp. 609-626.

35. Orsdemir, A.; Kemahlıglu-Ziya, E.; Parlakturk, A.K. Competitive quality choice and remanufacturing. Prod. Oper. Manag. 2014, 23, 48-64. [CrossRef]

36. White, A.L.; Stoughton, M.; Feng, L. Servicizing: The Quiet Transition to Extended Producer Responsibility; Technical report. Submitted to U.S. Environmental Protection Agency, Office of Solid Waste; Tellus Institute: Boston, MA, USA, 1999.

37. Petit-Boix, A.; Llorach-Massana, P.; Sanjuan-Delmás, D.; Sierra-Pérez, J.; Vinyes, E.; Gabarrell, X.; Rieradevall, J.; Sanyé-Mengual, E. Application of life cycle thinking towards sustainable cities: A review. J. Clean. Prod. 2017, 166, 939-951. [CrossRef]

38. Suhariyanto, T.T.; Wahab, D.A.; Rahman, M.N.A. Multi-life cycle assessment for sustainable products: A systematic review. J. Clean. Prod. 2017, 165, 677-696. [CrossRef]

39. Liu, Y.; Cheng, Y.; Chen, H.; Guo, S.; Lu, Y. Selling remanufactured products under one roof or two? A sustainability analysis on channel structures for new and remanufactured products. Sustainability 2018, 10, 2427. [CrossRef]

40. Esenduran, G.; Kemahlu-Ziya, E.; Swaminathan, J.M. Take-back legislation: Consequences for remanufacturing and environment. Decis. Sci. 2016, 47, 219-256. [CrossRef]

41. Subramanian, R.; Subramanyam, R. Key factors in the market for remanufactured products. Manuf. Serv. Oper. Manag. 2012, 14, 315-326. [CrossRef]

42. Ardito, L.; Dangelico, R.M. Firm environmental performance under scrutiny: The role of strategic and organizational orientations. Corp. Soc. Responsib. Environ. Manag. 2018, 25, 426-440. [CrossRef] 